\title{
Photocapture of dynamic hydrogen-bonded assemblies
}

\author{
Nathan D. McClenaghan and Dario M. Bassani ${ }^{\dagger}$ \\ Groupe de Chimie Supramoléculaire, Biomimétisme et Nanosciences, LCOO CNRS UMR 5802, \\ Université Bordeaux I, 33405 Talence, France
}

\begin{abstract}
Recent advances in the continuing study of [2+2] photodimerization reactions in supramolecular, non-covalent systems are presented. The covalent photocapture of small dynamic assemblies which are formed using weak hydrogen-bonding interactions between two different complementary units, barbiturates and melamines, is discussed. One unit serves as a photo-inert supramolecular template capable of bringing two photoactive units together using multiple hydrogen-bonds. The second type of unit unites the corresponding, complementary hydrogen-bonding motif with a photoactive unit. Irradiation of the supramolecular assemblies leads to photodimerization of adjacent units and generation of an imprinted site for the template. Moieties which are adapted to participate in photodimerization reactions are styrene, cinnamate, stilbene and fullerene units. The results are interpreted on the basis of topochemical reaction control.
\end{abstract}

\section{INTRODUCTION}

Photoreactions, like most reactions, are subject to both electronic and steric control. The former aspect is typically energetically dominant due to the high energy provided by excited states, thus contributing directly to enabling a specific reaction to take place. The latter aspect exerts a more subtle influence, principally on the geometrical and stereochemical aspects of the observed photoproducts. Typically, in the case of [2+2] photodimerization reactions, the products obtained depend on the relative geometries of two interacting components adopted during the lifetime of the excited state. Whilst the study of electronic properties of excited states constitutes a central theme in photochemistry, the effect of steric and other non-covalent interactions on the reactivity of excited states is much less documented. This is probably due to the much weaker nature of these effects compared to electronic interactions, along with the difficulty in assessing the precise orientation of components in homogeneous solution (reports of photochemical transformations under topological control in the solid-state are more abundant) [1]. Investigation of supramolecular chemical assemblies is well adapted to redress this balance, using a range of non-covalent interactions to engineer assemblies of different components. Thus, the outcome of photochemical reactions may express the chemical programming in a multicomponent molecular system, as demonstrated in several ground-state examples [2]. In contrast to solid-state reactions, efforts to precisely design molecular components so that they will spontaneously organize into a photoreactive assembly in solution are complicated by such factors as background reactivity and the difficulty in demonstrating the intervention of the proposed architecture [3].

\footnotetext{
${ }^{\dagger}$ E-mail: d.bassani@lcoo.u-bordeaux1.fr
}

The wealth of information, mostly from X-ray crystallographic data, concerning the geometrical requirements of the dimerization of cinnamic acid derivatives makes them an appealing starting point for the design of supramolecular systems and will form the basis for a large part of the ensuing discussion [4]. In the current instance, the intermolecular supramolecular interactions involve hydrogen-bonding in solution. This was used for the first time by Beak and Ziegler over 20 years ago to accelerate a typically inefficient photocycloaddition reaction in solution [5]. More recently, Bach and co-workers have used intermolecular hydrogen bonding to exert stereochemical control of photoinduced cycloaddition reactions [6]. Along similar lines Feldman et al. [7] constructed hydrogen-bonded assemblies in the solid state. Their results indicated the near quantitative formation of the $\alpha$-truxillate (see Figure 3 ) in the solid state with an extremely low photoreactivity in solution. Recent reports of cinnamate/cinnamic acid photodimerization in diverse supramolecular systems also include reversed micelles [8] and Langmuir-Blodgett films [9]. Another elegant approach using non-covalent interactions to promote photodimerization utilizes hydrophobic forces to accelerate and direct photochemical cycloaddition reactions within a $\beta$-cyclodextrin reaction vessel, as demonstrated for the dimerization of coumarin molecules [10].

\section{SUPRAMOLECULAR CATALYSIS OF [2 + 2] PHOTODIMERIZATION REACTIONS}

Recent work on hydrogen-bonding systems has put forward several leading molecular candidates where multiple complementary hydrogen bonding motifs conspire to generate diverse supramolecular edifices. Among the more studied examples are those generated from combinations of barbiturates (1) and melamines (2) in 
a)
1: $\mathrm{R}=\mathrm{H}$
1a: $\mathrm{R}=$ Ethyl
1b: $\mathrm{R}=\mathrm{n}-\mathrm{Hexyl}$

2a: $\mathrm{R}=\mathrm{n}$-Octyl

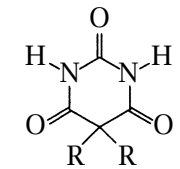<smiles>[R]Nc1nc(N[R])nc(N[TlH])n1</smiles>

b)

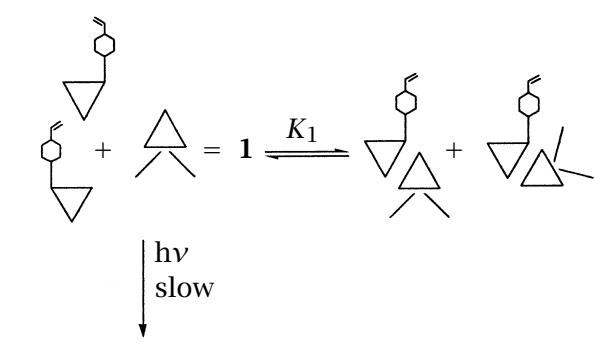

MIXTURE OF DIMERS

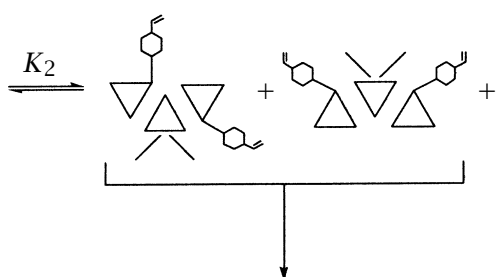

NO PHOTOREACTION
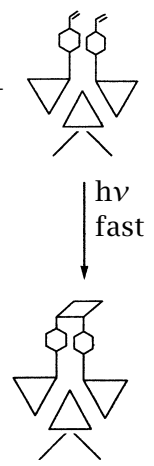

Figure 1. Linear tapes derived from barbiturates (1) and melamines (2), (a); schematic representation of the photocapture of dynamic multicomponent assemblies (b).

aprotic solvents, as shown in Figure 1. Whilst in Figure 1a one can recognise a linear "tape"-like structure formed from combinations of unencumbered barbiturates and melamines, Whitesides and colleagues demonstrated that some degree of control can be imposed on the specific supramolecular structures generated as bulky substituents result in crinkled tape and rosette-like structures [11].

Taking these relatively weak non-covalent interactions as a starting point for the design of functional architectures, it was surmised that photodimerizable moieties could be appended onto these units and subsequently precisely orientated [12]. This approach involves the combination of three separate components, one of which serves as a "supramolecular catalyst." Its role is to reversibly bind two photoreactive species in a geometry favorable for the photoinduced reaction (other geometries result in little or no photodimerization).

In the case of $[2+2]$ photodimerization reactions, the formation of a rigid cyclobutane structure effectively "locks in" the geometry of the reagents, thus allowing the covalent capture of the dynamic supramolecular architecture. This general approach is summarised in Figure 1b, where the face-to-face (syn) geometry is anticipated to lead to the most efficient photodimerization reactions [13]. Provided the reaction in presence of template is faster, the equilibrium mixture will shift towards the templated products.

Some of the molecules designed to demonstrate the approach outlined above are shown in Figure 2 [14]. In each of 3-6 one can recognise a melamine appended with one of the following photodimerizable units (see data in Table 1):- cinnamate (3 and 6), styrene (4) or stilbene (5). These molecules are unsymmetrical and hydrogen bonding is restricted to one side as the other is encumbered by an alkoxy group, reducing the number of possible structures obtained in the preirradiation mixture to those shown in Figure 1b. The specific role of the barbiturate unit $\mathbf{1} \mathbf{b}$ is to augment the rate of reaction between components through its capacity to orient reactive components within a supramolecular assembly. This is expected to be suited to photoreactions due to the relatively short-lifetimes of electronically excited states. The overall envisaged process therefore corresponds to that of Figure $1 \mathrm{~b}$ where the formation of the supramolecular assembly reposes upon the capacity of the symmetrical barbiturate to form closed three component structures using six hydrogen bonds, three with each melamine unit.

The binding of $\mathbf{3}$ to $\mathbf{1 b}$ is relatively strong as determined by NMR titration experiments $\left(\mathrm{CDCl}_{3}\right)$, 
Table 1. Binding constants, fluorescence emission and cis-/trans-isomerization data for 3-6.

\begin{tabular}{cccccc}
\hline Compound & $K_{1}{ }^{\mathrm{a}}\left(M^{-1}\right)$ & $K_{2}{ }^{\mathrm{a}}\left(M^{-1}\right)$ & $\lambda_{\mathrm{em}}{ }^{\mathrm{b}}(\mathrm{nm})$ & $\phi_{\mathrm{em}}{ }^{\mathrm{b}}$ & $\mathrm{pps}(Z: E)^{\mathrm{c}}$ \\
\hline $\mathbf{3}$ & $620 \pm 60$ & $420 \pm 40$ & 396 & 0.03 & $2.0: 1$ \\
$\mathbf{4}$ & $310 \pm 60$ & $620 \pm 140$ & 325 & 0.003 & - \\
$\mathbf{5}$ & $1200 \pm 120$ & $250 \pm 25$ & 390 & 0.09 & $5.5: 1$ \\
$\mathbf{6}$ & $520 \pm 54$ & $150 \pm 27$ & 390 & 0.04 & $1.1: 1$ \\
\hline
\end{tabular}

a Binding to $\mathbf{1 b}$, in $\mathrm{CDCl}_{3}$.

b In degassed dichloromethane, $\lambda_{\mathrm{ex}}=290 \mathrm{~nm}(4), \lambda_{\mathrm{ex}}=326 \mathrm{~nm}(3,5$ and 6$)$.

${ }^{\mathrm{c}}$ Composition of photostationary state from $E, Z$ isomerization $\left(\lambda_{\mathrm{ex}}=350 \mathrm{~nm}\right)$.

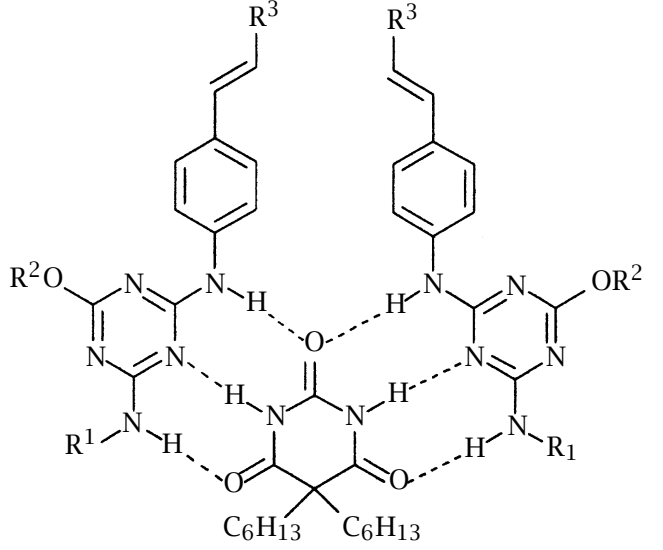

$1 \mathrm{~b}$

$$
\text { 3: } \mathrm{R}^{1}=\mathrm{H} ; \mathrm{R}^{2}=\mathrm{Me} ; \mathrm{R}^{3}=-\xi-\text { COOMe }
$$

4: $\mathrm{R}^{1}=\mathrm{H} ; \mathrm{R}^{2}=\mathrm{Me} ; \mathrm{R}^{3}=\mathrm{H}$

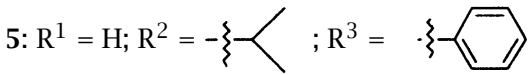

6: $\mathrm{R}^{1}=-3-10 ; \mathrm{R}^{2}=-\xi<\mathrm{R}^{3}=-\xi-$ COOMe

Figure 2. Melamines appended with photodimerizable units (3-6) and one $2: 1$ dynamic structure in the presence of supramolecular catalyst $\mathbf{1 b}$.

monitoring the association-dependent chemical shift of the amine and/or amide protons. The data were fitted to a 2 : 1 binding isotherm with binding constants of $\mathrm{K}_{1}=$ $620 \pm 60 \mathrm{M}^{-1}$ and $\mathrm{K}_{2}=420 \pm 40 \mathrm{M}^{-1}$ [15] consistent with the formation of the proposed trimeric architecture and a small degree of cooperative binding for the association of the second substituted melamine [16]. An important consideration for efficient photodimerization concerns the distance between reactive double bonds in the non-covalent assemblies. According to the energy-minimised trimeric stucture (PM3) incorporating, where appropriate, crystallographic values determined for related hydrogen-bonding species, reactive double bonds are placed at an estimated distance of $4.4 \AA$. Although this value is slightly larger than the ideal distance $(3.7 \AA)$ for yielding photodimers in the solid, flexibility in the framework can accommodate a closer approach [17].

In principle the $[2+2]$ cyclodimerization of cinnamates can yield eleven different products, commonly divided into two classes: those arising from a head-tohead dimerization (truxinates) and those from a headto-tail dimerization (truxillates), as illustrated in Figure 3. Whereas the preparation of $\alpha$ - and $\beta$-truxinic acid from the irradiation of solid samples of cinnamic acid is favoured, the remaining cyclobutane structures are typically minor products.

Irradiation of degassed solutions $\left(350 \mathrm{~nm}\right.$, in $\mathrm{CHCl}_{2}$, $10^{-2} \mathrm{M}$ ) of 3 was carried out in the absence of template, where cis-/trans-isomerization rapidly leads to the photostationary state (2: 1, Z: E). Chromatographic analysis of the photoproducts after prolonged irradiation indicates that one major and six minor products result. Identical experiments conducted in the presence of template $\mathbf{1 b}(0.5 \mathrm{eq})$ indicate that the rates of formation for three of the photoproducts is greatly enhanced. These were isolated by preparative HPLC and identified as the neotruxinate, $\beta$-truxinate and $\varepsilon$-truxillate dimers, with the major product as the head-to-head ( $\beta$-truxinate) dimer. The influence of the template is sufficiently strong to induce the formation of otherwise disfavoured products (including the head-to-tail $\varepsilon$ truxillate dimer), leading to the conclusion that the photodimerization is under topochemical control within the supramolecular assembly. Yields of the three predominant photodimers in the presence of $\mathbf{1 b}$ correspond to 3-10-fold enhancements. The quantum yield for the capture of the $\beta$-truxinate in the assembly was estimated to be 0.06 , at least a 75 -fold increase compared to solution. 
Truxillates

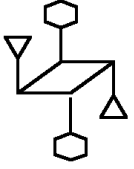

$\alpha$

$\underline{\text { Truxinates }}$

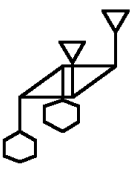

$\beta$

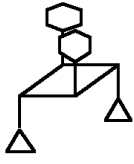

$\varepsilon$

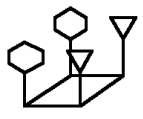

$\omega$

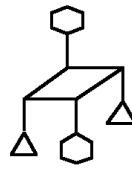

$\gamma$

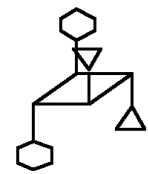

$\delta$

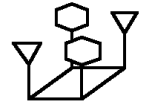

peri

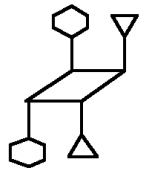

$\mu$

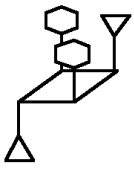

epi

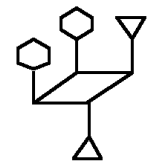

neo

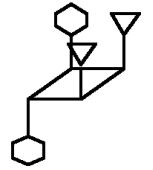

$\xi$

Figure 3. Complete library of possible cinnamate dimer structures (adapted from reference [4]).

The high solubility of 6 with respect to the other photoactive melamine species allowed the effect of concentration on the supramolecular catalysis to be investigated over a reasonably wide range. Double reciprocal plots $\left(1 / \Phi_{(\mathrm{dim})}\right.$ vs. $\left.1 /[6]\right)$ for the formation of the three predominant isomers listed above in the presence of 0.5 eq of $\mathbf{1 b}$ showed a linear relationship, suggesting the intervention of one excited-state. In the case of the untemplated reaction, pronounced downward curvature was observed. Factors that may be considered to affect the dimerization process include the formation of photoactive aggregates at higher concentration and dimerization via both singlet and triplet excited states [18]. Limiting quantum yields of dimerization from the intercepts in the plot of the templated reaction correspond to values of $1.3 \times 10^{-3}$ for the $\beta$-truxinate and $2.3 \times 10^{-4}$ for the other two major isomers within the supramolecular assembly.

\section{MOLECULAR IMPRINTING: SUBSTRATE-INDUCED RECEPTOR SYNTHESIS}

The idea of using a guest to imprint a binding site specific to itself was initially proposed by Linus Pauling, who believed that this procedure was utilised in Nature to effect the formation of receptors with very high guest-specificity in enzymes. Although this proved not to be the case in these biological systems, this idea inspired a new generation of chemists and the area of "molecular imprinting" was born. Typically, approaches to molecular imprinting have been largely restricted to 3D-pockets in polymers for a wealth of guests $[19,20]$.

The supramolecular systems considered herein can also be considered to provide an approach to covalent photo-"writing" of a receptor site from non-covalent architectures with guest-inclusion. Selectivity and strong binding are assured in the structure obtained postirradiation, as only architectures amenable to subsequent guest rebinding are generated. Taking the photodimer $(5)_{2}$ as an example, the structural rigidity of the diphenylcyclobutane scaffold and high density of hydrogen-bonding donor acceptor sites in the photodimers are the origin of their binding properties. This was demonstated in their capability of discriminating between structurally similar pyrimidine-bases (nucleic acid fragments) such as thymine and uracil [21]. An NMR titration to measure the rebinding of Barbital (5,5-diethylbarbituric acid, 1a) showed an association constant of $2400 \mathrm{M}^{-1}$. Thus the preparation of receptors via light-induced capture of supramolecular assemblies can lead to functional receptors, of similar binding affinity as those reported by conventional synthetic methodologies [22].

An important consideration common to the use of non-covalent templates to maintain and orient reactants during a bond forming reaction is that the reaction products usually present higher affinity for the template than the starting materials. This apparent drawback which diminishes turnover in these supramolecularly catalysed reactions can be bypassed by the use of stoichiometric proportions of template.

Strong and specific guest-binding coupled with facile chemical derivatization (via the easily hydrolyzed cyclobutane methyl esters), make these photogenerated species interesting candidates for the development of molecular receptors.

\section{SUPRAMOLECULAR TEMPLATE PROMOTED FULLERENE-ADDUCT FORMATION}

A final class of molecules we shall consider are substituted fullerenes. The photodimerization of pristine fullerene has been found to be efficient in the 

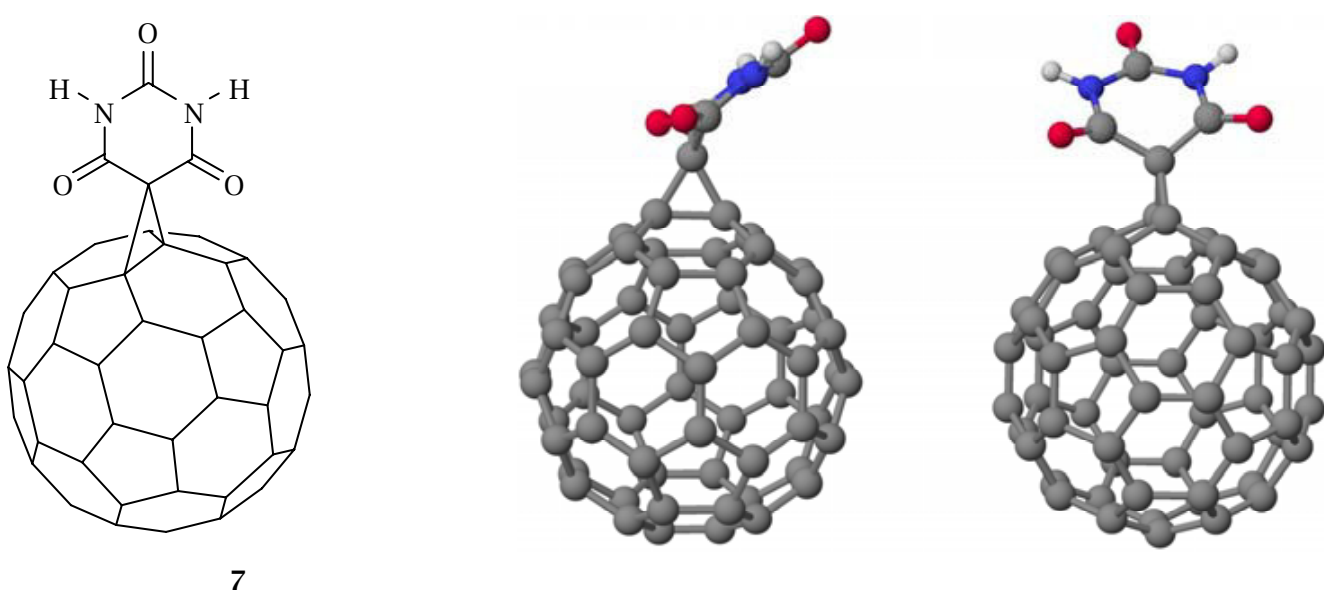

Figure 4. Structural formula and calculated structure (PM3 calulations) of barbituric acid-fullerene dyad 7.

solid state [23], proceeding through the intermediacy of a ${ }^{3} \mathrm{C}_{60} *$ unit which reacts with a ground-state fullerene [24]. Conversely, the light-induced dimerization of fullerenes in homogeneous solution has proved challenging, partly due to the low solubility of fullerene. Hummelen et al. recently reported the photodimerization of fullerene in homogeneus solution in an intramolecular fashion [25]. However, the corresponding intermolecular reaction has not been previously demonstrated. The templated photoreactions, as outlined above, are well-adapted to address this challenge. The envisaged building block 7 , which incorporated a hydrogen-bonding molecular recognition motif is shown in Figure 4 [26].

This species varies from the previous examples, not only in the choice of photodimerizable unit, but also because the photodimerizable substituent is introduced on the barbituric acid moiety. A degree of distortion is induced in the barbituric acid unit due to the close approach of the fullerene cage to the barbituric acid carbonyl oxygens in the 4- and 6-positions, as suggested by the molecular modelling (PM3 calculations) and confirmed by ${ }^{13} \mathrm{C}$-NMR spectra [27]. A similar molecular geometry was proposed for structurally related Nalkylated fullerene-barbiturates in separate reports by Hirsch and Diederich [28]. Despite this apparent distortion and deviation from planarity, molecule 7 should participate in efficient hydrogen-bonding, making this building block suitable for the present study [29, 30].

In the presence of the complementary melamine derivative several complexes may be formed, one of which places two fullerene units in close proximity. This is shown schematically in Figure 5, and the specific double bonds which may be implicated in photodimerization processes are depicted in Figure 5b. Whilst the first substitution of the fullerene cage is known to pro- ceed across one of the thirty equivalent reactive $[6,6]$ double bonds in fullerene, the number of possible isomers obtained by a second reaction is rather large. For example, for a doubly substituted methanofullerene, nine different double bonds are available for the second attack [31]. We find it significant that molecular modelling suggests that for the dimerization reaction of the fullerene cage, the supramolecular templating approach places only one out of nine different double bonds in close enough proximity to react, which would underline the extremely high degree of specificity presented by this approach.

Irradiation of an assembly such as the one shown in Figure 5a would be expected to lead to efficient photodimerization, in line with the findings outlined above. Thus, irradiation of dilute $\left(5 \times 10^{-4} \mathrm{M}\right)$ solutions of 7 and a $1: 1$ mixture of $2 \mathrm{a}$ and 7 in degassed $o$ dichlorobenzene $(o$-DCB) resulted in the gradual disappearance of 7 as shown by HPLC analysis. To identify the photoproducts, the irradiated solutions were subsequently analyzed by MALDI-TOF MS. A typical result is shown in Figure 6, where it can be seen that in the case of samples containing the melamine template, a clear signal for the $(7)_{2}$ dimer is observed. To the best of our knowledge, this represents the first example of intermolecular photodimerization of a fullerene derivative in solution. Additional signals due to fragmentation are also evidenced including the $(7)_{2}$ dimer having lost one barbiturate, along with regeneration of parent $\mathrm{C}_{60}$ and monomer 7 .

In the absence of the melamine-based template $\mathbf{2 a}$, no signals corresponding to the formation of either $\mathrm{C}_{60}$ dimer or $(7)_{2}$ could be detected by MALDI-TOF MS under identical irradiation conditions. However, it is interesting to note that a small dimer signal is observed in the MS spectrum of the mixtures of $\mathbf{7}$ and $\mathbf{2 a}$ even in 
a)

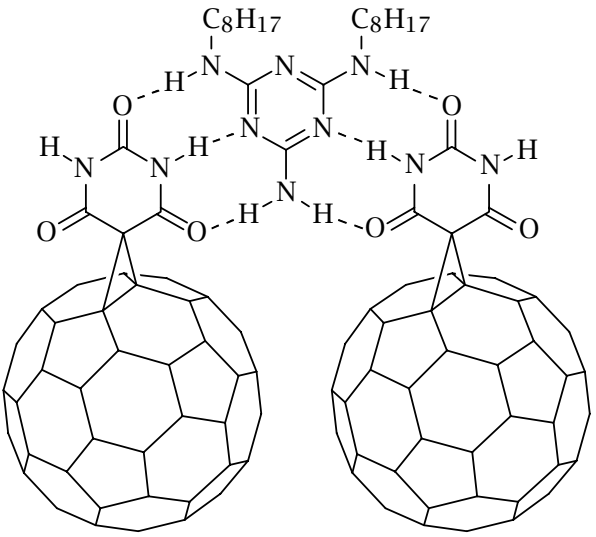

b)

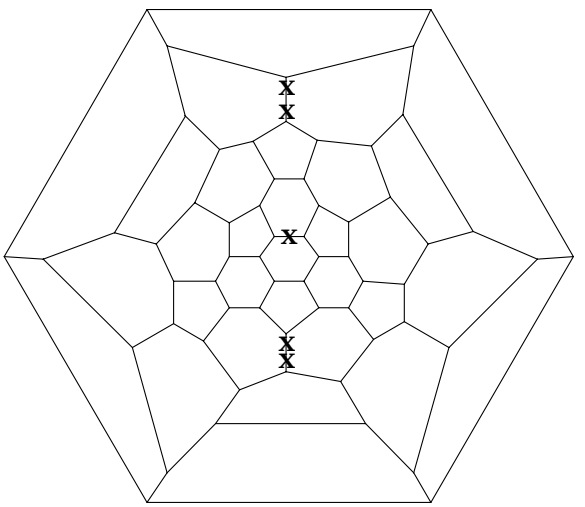

Figure 5. Possible 1 : 2 supramolecular assembly amenable to photodimerization (a); a Schlegel diagram showing pertinent double bonds in this process (b). $\mathbf{x}=$ Barbiturate substituent; $\mathbf{x} \mathbf{x}=$ equivalent double bonds available for photodimerization . Numbering and double bonds are omitted for clarity.

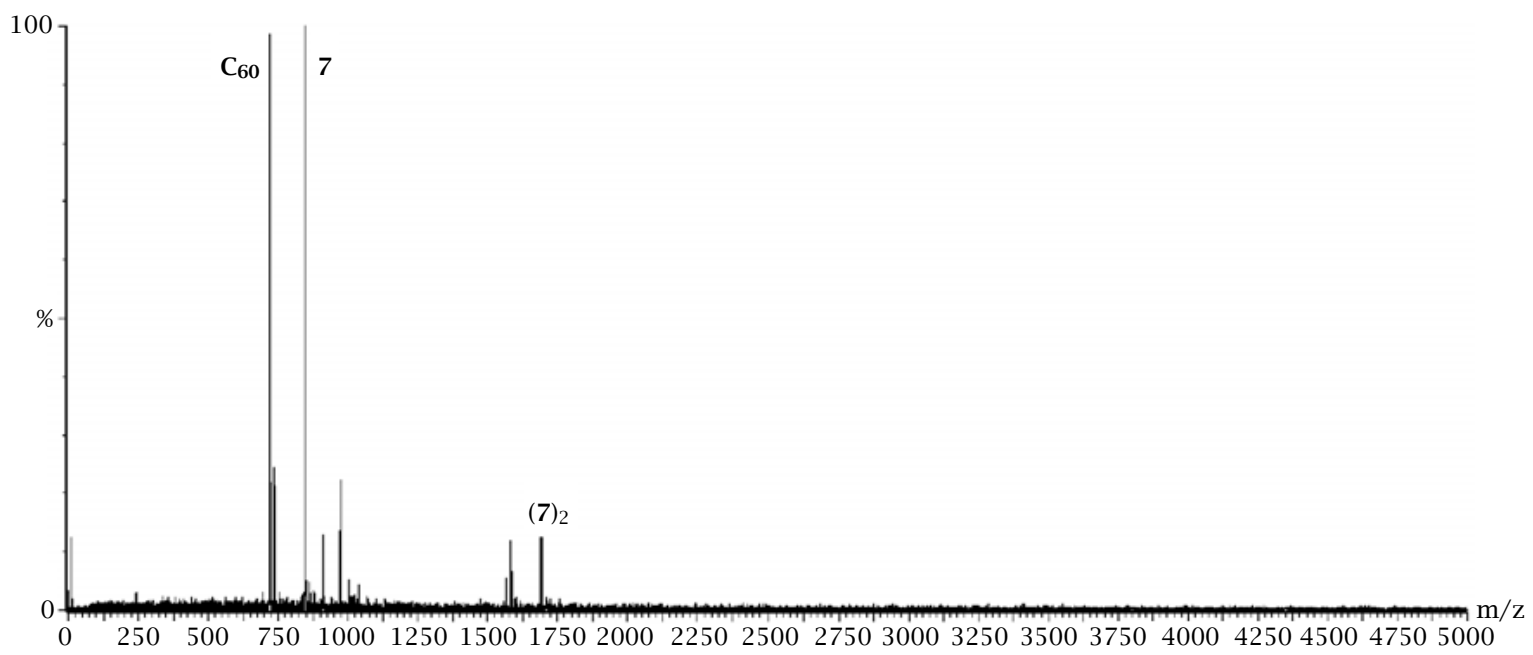

Figure 6. MALDI-TOF spectrum of solution of 7 and 2a (1: 1 stoichiometry) after short irradiation times. Peaks at 720 ( $\left.\mathrm{C}_{60}\right)$ and 1566 correspond to the loss of a barbiturate moiety from 7 and $(7)_{2}$, respectively. (Adapted from reference [26]).

the absence of prior irradiation (control experiments). We believe that this results from photoinduced dimerization upon desorption/ionization using the $\mathrm{N}_{2}$ laser $\left(\lambda_{\text {irr }}=337 \mathrm{~nm}\right)$ in the MALDI TOF apparatus, and points to the formation of organized binary hydrogen-bonded structures in the solid.

Unlike the systems described in previous sections where the photoproducts are restricted to dimers, in the current instance the possibility exists to form extended fulleropolymers in a linear fashion leading to the idea of molecular wires etc. Sequential photodimerization processes require slightly different reactions in that in the first instance a singly substituted cage reacts with an adjacent fullerene cage, whereas the second step requires reaction of a doubly substituted cage to form the tri-substituted cage. Although the magnitude of the binding constants in these melaminebarbituric acid systems are generally insufficient for the formation of extended tape-like structures, stepwise dimerization may provide a supramolecular route to the formation of elusive linear fulleropolymer structures of 7 in the presence of 2a. Unfortunately, although prolonged irradiation leads to complete consumption of 7 , no signals corresponding to the formation of 
extended poly(fullerene) structures are identifiable by MS. However, heating the irradiated solutions (refluxing $o$-DCB, $5 \mathrm{~min}$ ) does result in the formation of 7 and $\mathrm{C}_{60}$, a behavior that is often associated with thermal scission of poly(fullerene) structures. Further work on the unambiguous identification of the adducts formed upon irradiation and generation of more highly organised photoactive supramolecular multi-fullerene systems [32], conducive to higher fullerene adduct formation, is in progress.

\section{CONCLUSION}

Supramolecular catalysis, operating through molecular recognition can be used to enhance and direct excitedstate reactions. This is evidenced by the augmentation of reaction rates and quantum yields for photodimerization reactions inside non-covalent trimeric architectures using a variety of photoactive groups. Additionally, the distribution of photoproducts can be drastically altered by the presence of the appropriate template. As the photocaptured rigid cyclobutane structures retain a "memory" of the pre-irradiation structure, they also serve as examples of substrate-induced molecular receptor synthesis.

\section{ACKNOWLEDGMENT}

This work was supported by the CNRS and the MRT (ACI Nanosciences-Nanotechnologies).

\section{REFERENCES}

[1] G. M. J. Schmidt, Pure Appl. Chem. 27 (1971), 647; Y. Ito, Molecular and Supramolecular Photochemistry, Vol. 3, (V. Ramamurthy and K. S. Schanze, Eds.), Marcel Dekker, New York, 1999.

[2] J.-M. Lehn, Chem. Eur. J. 6 (2000), 2097; J.-M. Lehn, Supramolecular Chemistry-Concepts and Perspectives, VCH, Weinheim, 1995.

[3] M. Yoshizawa, Y. Takeyama, T. Kusukawa, and M. Fujita, Angew. Chem., Int. Ed. 41 (2002), 1347.

[4] For a discussion of the mechanism of cinnamate photodimerization see: D. M. Bassani, CRC Handbook of Organic Photochemistry and Photobiology, 2nd Ed., (W. Horspool and F. Lenci, Eds.), 2003, Chapter 20; F. D. Lewis, S. L. Quillen, J. E. Elbert, S. Schneider, and P. Geiselhart, J. Photochem. Photobiol. A 47 (1989), 173.

[5] P. Beak and J. M. Ziegler, J. Org. Chem. 46 (1981), 619.

[6] T. Bach, H. Bergmann, and K. Harms, Org. Lett. 3 (2001), 601.

[7] K. S. Feldman, R. F. Campbell, J. C. Saunders, C. Ahn, and K. M. Masters, J. Org. Chem. 62 (1997), 8814 .
[8] T. Nakamura, K. Takagi, and Y. Sawaki, Bull. Chem. Soc. Jpn. 71 (1998), 909; K. Takagi, H. Fukaya, N. Miyake, and Y. Sawaki, Chem. Lett. (1988), 1053; Y. Nakamura, J. Chem. Soc., Chem. Commun. (1988), 477; O. Ohtani, R. Sasai, T. Adachi, I. Hatta, and K. Takagi, Langmuir 18 (2002), 1165.

[9] J. Zhao, H. R. Hafiz, H. Akiyama, K. Tamada, and F. Nakanishi, Mol. Cryst. Liq. Cryst. A 322 (1998), 233; J. Zhao, H. Akiyama, K. Abe, Z. Liu, and F. Nakanishi, Langmuir 16 (2000), 2275; J. Zhao, K. Abe, H. Akiyama, Z. Liu, and F. Nakanishi, Langmuir 15 (1999), 2543; M. Yamamoto, N. Furuyama, and K. Itoh, J. Phys. Chem. 100 (1996), 18483.

[10] J. N. Moorthy, K. Venkatesan, and R. G. Weiss, J. Org. Chem. 57 (1992), 3292; T. J. Brett, J. M. Alexander, and J. J. Stezowski, J. Chem. Soc., Perkin Trans. 2 (2000), 1095; T. J. Brett, J. M. Alexander, and J. J. Stezowski, J. Chem. Soc., Perkin Trans. 2 (2000), 1105.

[11] E. E. Simanek, X. Li, I. S. Choi, and G. M. Whitesides, Comprehensive Supramolecular Chemistry, (J.-M. Lehn, Ed.), Pergamon, New York, Vol. 9, 1996, Chapter 17.

[12] D. M. Bassani, V. Darcos, S. Mahony, and J.-P. Desvergne, J. Am. Chem. Soc. 122 (2000), 8795.

[13] H. Greiving, H. Hopf, P. G. Jones, P. Bubenitschek, J.-P. Desvergne, and H. Bouas-Laurent, Liebigs Ann. (1995), 1949.

[14] V. Darcos, K. Griffith, X. Sallenave, J.-P. Desvergne, C. Guyard-Duhaon, B. Hasenknopf, and D. M. Bassani, Photochem. Photobiol. Sci. (2003), 1152.

[15] The program EQNMR was used to fit the experimental data. M. J. Hynes, J. Chem. Soc., Dalton Trans. (1993), 311.

[16] K. A. Connors, Binding Constants, Wiley Interscience, New York, 1987.

[17] J. A. Zerkowski, J. C. MacDonald, C. T. Seto, D. A. Wierda, and G. M. Whitesides, J. Am. Chem. Soc. 116 (1994), 2382.

[18] J. C. Dalton and J. J. Snyder, Mol. Photochem. 6 (1974), 291.

[19] See for example:- G. Vlatakis, L. I. Andersson, R. Muller, and K. Mosbach, Nature 361 (1993), 645; J.-D. Marty, M. Mauzac, C. Fournier, I. Rico-Lattes, and A. Lattes, Liq. Cryst. 29 (2002), 529.

[20] J. Damen and D. C. Neckers, J. Am. Chem. Soc. 102 (1980), 3265.

[21] D. M. Bassani, X. Sallenave, V. Darcos, and J.-P. Desvergne, Chem. Commun. (2001), 1446.

[22] S. R. Collinson, T. Gelbrich, M. B. Hursthouse, and J. H. R. Tucker, Chem. Commun. (2001), 555; S. K. Chang, D. Van Engen, E. Fan, and D. A. Hamilton, J. Am. Chem. Soc. 113 (1991), 7640.

[23] A. M. Rao, P. Zhou, K. A. Wang, G. T. Hager, J. M. Holden, Y. Wang, W. T. Lee, X.-X. Bi, P. C. Eklund, D. S. Cornett, M. A. Duncan, and I. J. Amster, Science 259 (1993), 955; P. Zhou, Z.-H. Dong, 
A. M. Rao, and P. C. Eklund, Chem. Phys. Lett. 211 (1993), 337; Y.-P. Sun, B. Ma, C. E. Bunker, and B. Liu, J. Am. Chem. Soc. 117 (1995), 12705.

[24] Y. Wang, J. M. Holden, Z.-H. Dong, X. X. Bi, and P. C. Eklund, Chem. Phys. Lett. 211 (1993), 341.

[25] J. Knol and J. C. Hummelen, J. Am. Chem. Soc. 122 (2000), 3226.

[26] N. D. McClenaghan, C. Absalon, and D. M. Bassani, J. Am. Chem. Soc. 125 (2003), 13004.

[27] 31 aromatic carbon resonances were observed instead of the 16 normally observed for a methanofullerene of $\mathrm{C}_{2 \mathrm{v}}$ symmetry.

[28] A. P. G. Robinson, R. E. Palmer, T. Tada, T. Kanayama, J. A. Preece, D. Philp, U. Jonas, and F. Diederich, Chem. Phys. Lett. 289 (1998), 586; I. Lamparth, G. Schick, and A. Hirsch, Liebigs. Ann./Recueil (1997), 253.

[29] D. M. Bassani, N. D. McClenaghan et al., in preparation.

[30] Other hydrogen-bonding fullerenes:- L. Sánchez, M. T. Rispens, and J. C. Hummelen, Angew. Chem., Int. Ed. 41 (2002), 838; M. T. Rispens, L. Sánchez, J. Knol, and J. C. Hummelen, Chem. Commun. (2001),
161; J. J. González, S. González, E. M. Priego, C. Luo, D. M. Guldi, J. de Mendoza, and N. Martín, Chem. Commun. (2001), 163; Z. Shi, Y. Li, H. Gong, M. Liu, S. Xiao, H. Liu, H. Li, S. Xiao, and D. Zhu, Org. Lett. 4 (2002), 1179; S. Xiao, Y. Li, H. Fang, H. Li, H. Liu, Z. Shi, L. Jiang, and D. Zhu, Org. Lett. 4 (2002), 3063; F. Diederich, L. Echegoyen, M. Gómez-López, R. Kessinger, and J. F. Stoddart, J. Chem. Soc., Perkin Trans. 2 (1999), 1577; E. H. A. Beckers, A. P. H. J. Schenning, P. A. van Hal, A. El-ghayoury, L. Sánchez, J. C. Hummelen, E. W. Meijer, and R. A. J. Janssen, Chem. Commun. (2002), 2888; D. M. Guldi, J. Ramey, M. V. MartínezDíaz, A. de la Escosura, T. Torres, T. Da Ros, and M. Prato, Chem. Commun. (2002), 2774; M. GutiérrezNava, H. Nierengarten, P. Masson, A. Van Dorsselar, and J.-F. Nierengarten, Tet. Lett. 44 (2003), 3043.

[31] A. Hirsch, I. Lamparth, and V. Karfunkel, Angew. Chem., Int. Ed. 106 (1994), 453.

[32] For fullerene organization via $\mathrm{Cu}^{\mathrm{II}}$-pyridine interactions: M. El Bakkari, N. D. McClenaghan, and J.-M. Vincent, J. Am. Chem. Soc. 124 (2002), 12942. 


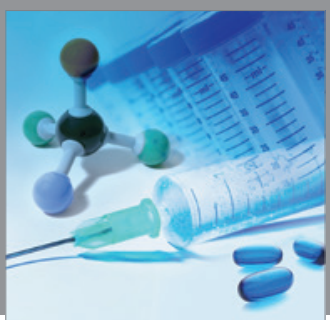

International Journal of

Medicinal Chemistry

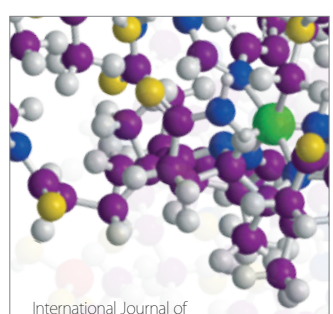

Carbohydrate Chemistry

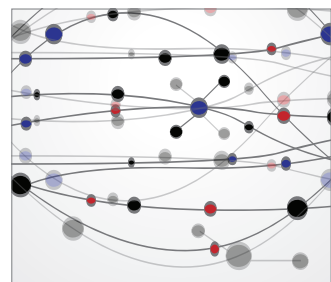

The Scientific World Journal
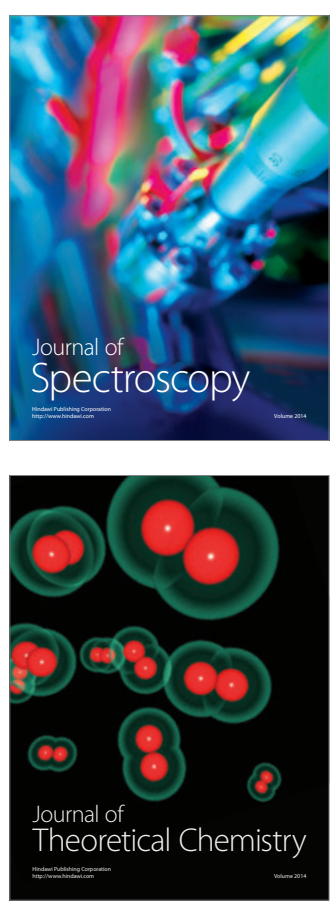
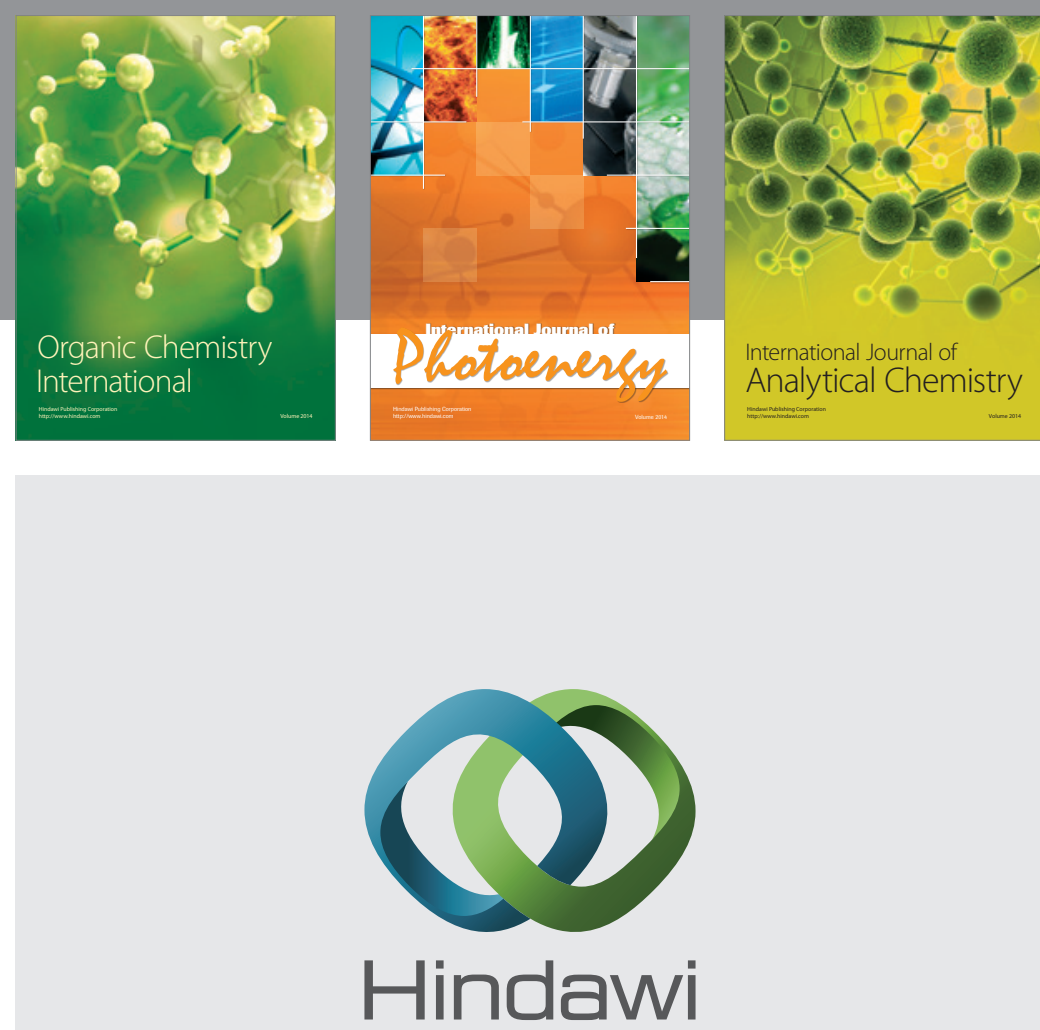

Submit your manuscripts at

http://www.hindawi.com
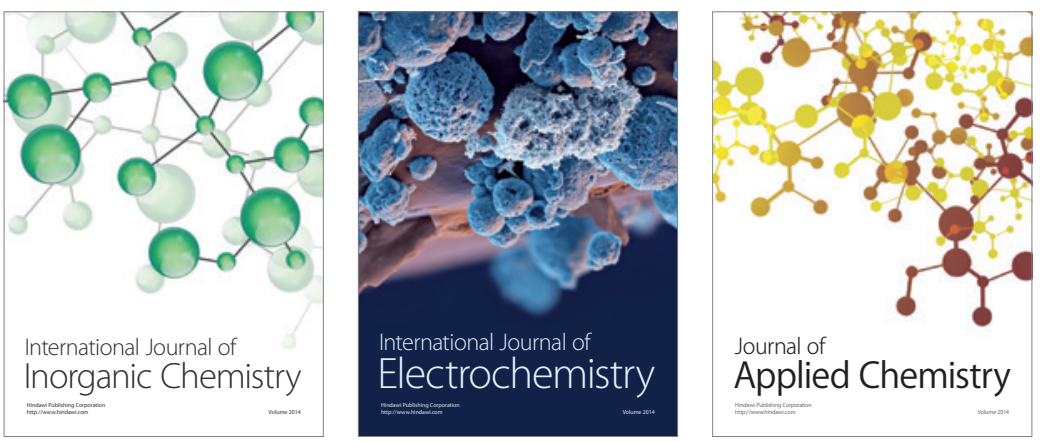

Journal of

Applied Chemistry
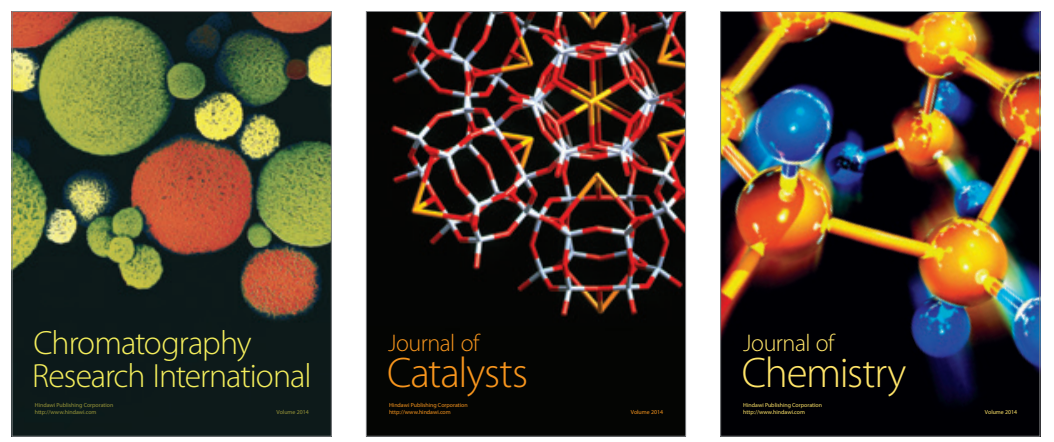
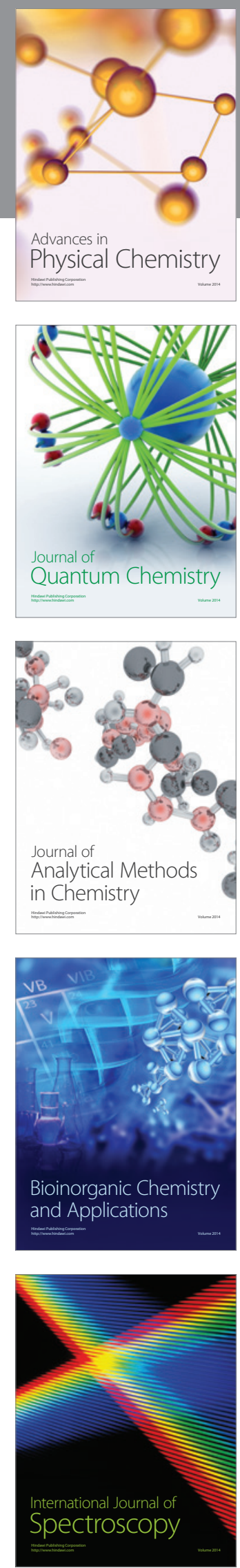